\title{
Epidemiology and Clinical Outcome of Snakebite in Western Nepal: A Retrospective Study
}

\author{
Karki $\mathrm{D}^{1^{*}}$, Sharma $\mathrm{B}^{2}$, Koirala $\mathbf{R}^{3}$, Nagila $\mathrm{A}^{4}$ \\ 'Department of Internal Medicine, Manipal College of Medical Sciences \& Teaching Hospital, Pokhara, Nepal \\ ${ }^{2}$ Department of Community Medicine, ${ }^{4}$ Department of Biochemistry, \\ Gandaki Medical College \& Teaching Hospital. Pokhara, Nepal. \\ ${ }^{3}$ Institute of Medicine, Pokhara Nursing Campus, Pokhara, Nepal.
}

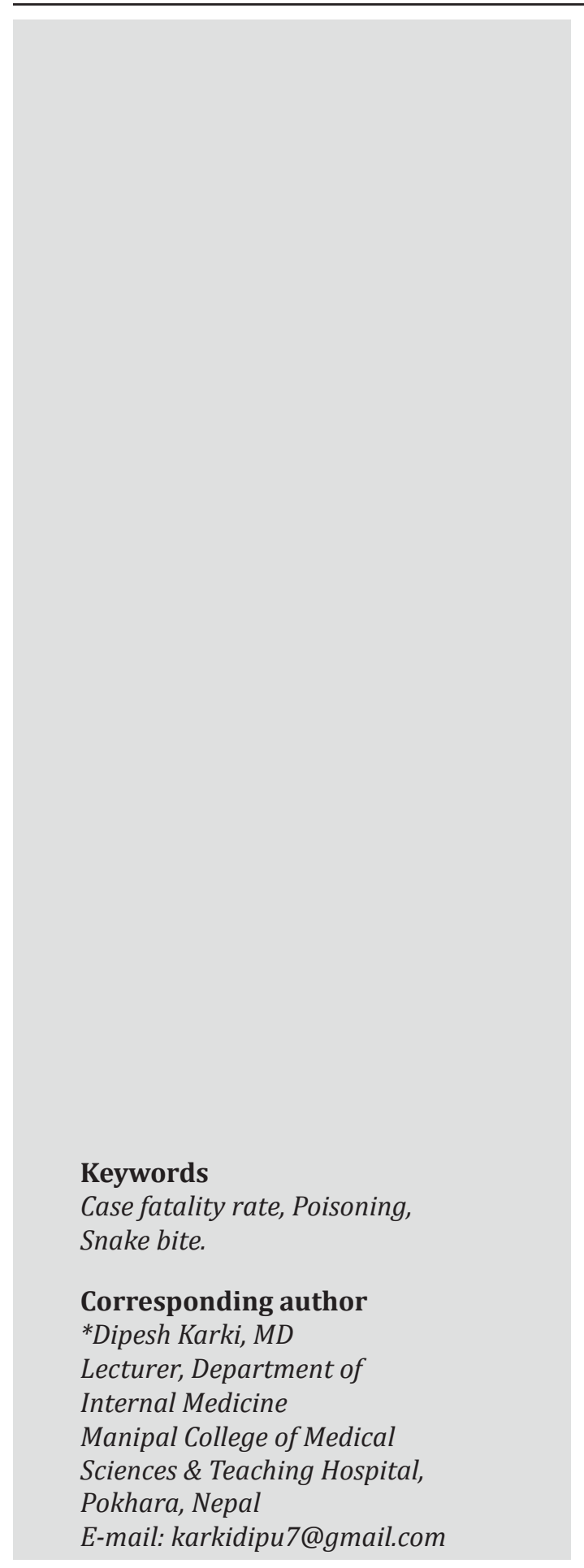

ABSTRACT

Introduction: Snakebite is an environmental hazard associated with significant morbidity and mortality. It is an important medical emergency and cause of significant numbers of hospital admissions in many parts of the Asian region. In this study, we assess the epidemiology and clinical outcome of snake bite.

Methods: This was a retrospective study of all patients with snake bites admitted to the Department of Internal Medicine, Manipal Teaching Hospital, Pokhara, kaski, Nepal. A total numbers of 265 snake bite cases in the period of 2013 to 2016 were enrolled in this study. Snake bite cases by person, place and time along with month of snake bite and time of bite, were analyzed. We also identified the types of snake and site of the bite. Sign and symptoms were clinically observed and the management of the snake bite cases was clinically done. Prothrombin time (PT) test along with INR value was performed by Medical Technologist at the Department of Laboratory, Manipal Teaching Hospital. Data was entered in to the Microsoft excel and analyzed by SPPS version 21.0. Percentages were applied to find the results.

Results: Total numbers of snake bite cases were 265. More than half, $60.4 \%$ of the snake bite cases were females. Regarding the age group, nearly half, $47.9 \%$ were in the age group of 20 - 40 years and $9.8 \%$ cases were in the age group of 60 years and above. In this study, $50.6 \%$ bite cases were held at the day time and most of the bites were reported/ observed in the limb, 53.6\% in lower limb, and $43.4 \%$ in the upper limb. Very few bites were in the head, neck and trunk. Our result shows $49.1 \%$ were green snake and $30.9 \%$ snake were unidentified. When we observed the sign and symptoms, 153 (57.7\%) cases showed local swelling, 83 (31.3\%) showed fang mark. Hematological manifestation were 144 (54.3\%) cases and complication observed in 145 (54.7\%) cases. Snake bite cases were managed after PT/INR test, INR. Antibiotic were prescribed in 154 cases and in 135 (50.9\%) cases blood was transfused. There were no fetal cases noticed among hospital admitted snake bite cases.

Conclusion: There is gross disparity in the management and outcomes of snake bite in different hospitals. Snake bite cases should manage in tertiary care hospital as early as possible. 


\section{INDRODUCTION}

Snakebite is an environmental hazard associated with significant morbidity and mortality. It is an important medical emergency and cause of significant numbers of hospital admissions in many parts of the Asian region ${ }^{1}$. Although high snakebite mortality is often reported to occur in India, the highest incidence of venomous yet snakebite has not been a prioritized public health issue in Nepal ${ }^{2,3}$. The Snake bite has been considered to be a devastating environmental occupational injury, affecting poor rural communities like farmers, plantation workers and fishermen around the world ${ }^{4}$. The incidence of bites is high in warm regions, where snakes are abundant and economic activities are mainly agricultural. Among 3,000 known species of snakes, only 200 are poisonous to humans. Snakebite is a widely distributed but neglected condition. Viper species are most often involved, the victims are primarily men, and the most common site of the bite is the upper limbs. The clinical presentation caused by snakebite varies with the species involved and most of the viper venoms exhibit both anticoagulant and coagulant effects $^{5}$. In Asia alone, it has been estimated that 4 million snakebites occur each year, of which approximately $50 \%$ are envenomed, resulting in 100,000 annual deaths. The incidence is particularly high in rural areas of warm regions where snakes are abundant and human activities, mainly agriculture, increase the risks of snake encounters. Case fatality rates can be high where patients do not have rapid access to life-saving Anti-Snake Venom Serum (ASVS), a common situation in rural areas of developing countries ${ }^{5}$. World Health Organization reported venomous snakes caused 5.4 million bites every year around the world, of them 2.5 million suffered with envenoming and around 125,000 $\mathrm{died}^{4}$. The incidence is quite high in rural warm regions of Terai and even in the mountainous region of the Nepal. Envenomation is an occupant hazard for the farmers and farm labors, plantation workers, herders and hunters in tropical and subtropical countries. Although the exact incidence is unknown, about $20 \%$ of the bites result in no envenomation and $10 \%$ result in mortality; the actual incidence of snake bites may be much higher ${ }^{6,7}$. The snake venom contains many enzymes like digestive hydrolases, hyaluronidase, and activators or inactivators of physiological processes which include L-amino acid oxidase, phosphomono and diesterase, 5'-nucleotidase, DNAase, NAD-Nucleosidase, phospholipase A2, and peptidases $^{8}$. Some snake venom, contains carbohydrates (glycoprotein) lipids and biogenic amines while other venom contain free amino acids $s^{9,10}$.

\section{MATERIALS AND METHODS}

Manipal Teaching Hospital is situated in Pokhara, kaski district in western development region. It is the only medical institution providing tertiary care facilities for the people residing in western development region of Nepal which constitutes about $20 \%$ of total population of Nepal it gets its referral from regional hospital, medical colleges and other zonal hospital and district hospital of Western Development Region of $\mathrm{Nepal}^{6}$.

This was a retrospective study of all patients with snake bites admitted to the Department of Internal Medicine, Manipal Teaching Hospital, Pokhara, kaski, Nepal. A total numbers of 265 snake bite cases in the period of 2013 to 2016 were enrolled in this study. Snake bite cases by person, place and time along with month of snake bite and time of bite, were analyzed. We also identified the types of snake and site of the bite. Sign and symptoms were clinically observed and the management of the snake bite cases was clinically done. The management of cases was done by PT and INR test. For PT and INR value, $3.0 \mathrm{ml}$ of venous blood sample was collected with standard protocol and test was performed by Medical Technologist at the Department of Laboratory, Manipal Teaching Hospital. Data entry was performed using the Microsoft excel and percentages were applied to find the results.

\section{RESULTS}

Total numbers of snake bite cases were 265. More than half $60.4 \%$ of the snake bite cases were females. Regarding the age group, nearly half, $47.9 \%$ were in the age group of 20 40 years and $9.8 \%$ cases were in the age group of 60 years and above. Mean age of the snake bite cases was 38.7 (SD \pm 16.32 ) with the range of 14 to 82 years. More than half, $58.1 \%$ cases were admitted from Kaski District followed by Syangja district (15.5\%) and Tanahun district (14.7\%). In the study, cases of snake bites were included from 2013 to 2016 . Out of total cases, $35.8 \%$ and $32.8 \%$ cases were collected in 2014 and 2016, respectively. Only, 14\% cases were admitted in the year 2013. Out of the total cases nearly one third, $31.3 \%$ cases were admitted in August. No cases were observed in January, February and December. Cases began to appear from March and peaked in August and gradually decreased. After August, higher proportion of cases, $22.3 \%$ and $17.7 \%$ were occurred in July and September, respectively. Regarding the time of bite, more than half, $50.6 \%$ bites were reported at day time, from 5 
AM to 7 PM.

Table 1: Distribution of snake bite cases by person, place and time $(\mathrm{N}=265)$

\begin{tabular}{|c|c|c|}
\hline Characteristics & Number & Percentage \\
\hline \multicolumn{3}{|l|}{ Sex } \\
\hline Males & 105 & $39.6 \%$ \\
\hline Females & 160 & $60.4 \%$ \\
\hline \multicolumn{3}{|l|}{ Age group } \\
\hline Below 20 & 29 & $10.9 \%$ \\
\hline $20-40$ & 127 & $47.9 \%$ \\
\hline $40-60$ & 75 & $28.3 \%$ \\
\hline$>60$ & 26 & $9.8 \%$ \\
\hline Missing & 8 & $3.0 \%$ \\
\hline Mean age & 257 & $38.7( \pm 16.32)$ \\
\hline \multicolumn{3}{|l|}{ Place of residence } \\
\hline Kaski & 154 & $58.1 \%$ \\
\hline Others & 18 & $6.8 \%$ \\
\hline Parbat & 13 & $4.9 \%$ \\
\hline Syangja & 41 & $15.5 \%$ \\
\hline Tanahun & 39 & $14.7 \%$ \\
\hline \multicolumn{3}{|l|}{$\begin{array}{l}\text { Year-wise distribu- } \\
\text { tion }\end{array}$} \\
\hline 2013 & 37 & $14.0 \%$ \\
\hline 2014 & 95 & $35.8 \%$ \\
\hline 2015 & 46 & $17.4 \%$ \\
\hline 2016 & 87 & $32.8 \%$ \\
\hline \multicolumn{3}{|l|}{ Seasonal Variation } \\
\hline March-June & 42 & $15.8 \%$ \\
\hline July & 59 & $22.3 \%$ \\
\hline August & 83 & $31.3 \%$ \\
\hline September & 47 & $17.7 \%$ \\
\hline October to November & 34 & $12.8 \%$ \\
\hline \multicolumn{3}{|l|}{ Bite time } \\
\hline Day time & 134 & $50.6 \%$ \\
\hline Night time & 84 & $31.7 \%$ \\
\hline Missing & 47 & $17.7 \%$ \\
\hline
\end{tabular}

Most of the bites were reported/observed in the limb, $53.6 \%$ in lower limb and $43.4 \%$ in the upper limb. Very few bites were in the head, neck and trunk. Of the total, $49.1 \%$ participants reported that they were bitten by green snake and $30.9 \%$ could not mention the type of snake.

Table 2: Site of bite and snake identified

\begin{tabular}{lcc}
\hline Variable & Frequency & Percentage \\
Site of the bite & & \\
Lower Limb & 142 & $53.6 \%$ \\
Upper Limb & 115 & $43.4 \%$ \\
Others & 8 & $3.0 \%$
\end{tabular}

\begin{tabular}{lcc}
$\begin{array}{l}\text { Type of snake } \\
\text { identified }\end{array}$ & \\
Black Snake & 13 & $4.9 \%$ \\
Green Snake & 130 & $49.1 \%$ \\
Not Identified & 23 & $8.7 \%$ \\
Others & 17 & $6.4 \%$ \\
Not mentioned & 82 & $30.9 \%$ \\
\hline
\end{tabular}

Out of the total cases included, $31.3 \%$ were presented with visible fang mark of snake. Of the total, $57.7 \%$ had developed local swelling and $4.2 \%$ had found with local bleeding. Of the total, $54.7 \%$ had developed some sort of complications. Of the total cases, $54.3 \%$ were found with hematological manifestation. Bruising was observed in $5.3 \%$ cases.

Table 3: Sign and symptoms of the snake bite

\begin{tabular}{lcc}
\hline $\begin{array}{l}\text { Signs observed } \\
\text { (multiple response- } \\
\text { question) }\end{array}$ & Frequency & Percentage \\
Fang mark visible & 83 & $31.3 \%$ \\
Local swelling & 153 & $57.7 \%$ \\
Local bleeding & 11 & $4.2 \%$ \\
Local necrosis & 2 & $0.8 \%$ \\
Complication & 145 & $54.7 \%$ \\
Hematological & 144 & $54.3 \%$ \\
manifestation & 14 & $5.3 \%$ \\
\hline Bruising & & \\
\hline
\end{tabular}

Regarding the management, $\mathrm{MgSO}_{4}$ dressing was done in $49.4 \%$. Of the total, $58.1 \%$ cases were provided antibiotics. PT was not found clot in the $39.6 \%$ cases. INR was 9 or did not clot in $46.4 \%$ cases. Therefore, more than half, $50.9 \%$ cases required blood transfusion.

Table 4: Management of the cases

\begin{tabular}{lcc}
\hline Variable & Frequency & Percentage \\
$\mathrm{MgSO}_{4}$ dressing done & 131 & $49.4 \%$ \\
Antibiotic prescribed & 154 & $58.1 \%$ \\
PT & & \\
Did not Clot & 105 & $39.6 \%$ \\
Clot & 160 & $60.4 \%$ \\
INR & & \\
$<4.5$ & 126 & $47.5 \%$ \\
$4.5-9$ & 15 & $5.7 \%$ \\
$>9$ or did not clot & 123 & $46.4 \%$ \\
Blood transfusion required & & \\
No & 130 & $49.1 \%$ \\
Yes & 135 & $50.9 \%$ \\
\hline
\end{tabular}




\section{DISCUSSION}

This study showed that most of the snake bite occurred in age 20 - 40 years which are in same in the study conducted in Western Region of Nepal ${ }^{1}$. More than half $60.4 \%$ of the snake bite cases were females. Regarding the age group, nearly half, $47.9 \%$ were in the age group of 20 - 40 years and $9.8 \%$ cases were in the age group of 60 years and above. Mean age of the snake bite cases was 38.7 (SD \pm 16.32 ) with the range of 14 to 82 years. It has been reported that snakebite largely affects the adolescent and young adults (10-30 years) ${ }^{12}$. More than half, $58.1 \%$ cases were admitted from Kaski District followed by Syangja district (15.5\%) and Tanahun district (14.7\%), which may be due to assessable, snake bite case admitted in Manipal Teaching Hospital, located at Pokhara, Kaski District.

In the study, cases of snake bites were included from 2013 to 2016 . Out of total cases, $35.8 \%$ and $32.8 \%$ cases were collected in 2014 and 2016, respectively. Only, 14\% cases were admitted in the year 2013. Out of the total cases nearly one third, $31.3 \%$ cases were admitted in August. No cases were observed in January, February and December. Cases began to appear from March and peaked in August and gradually decreased. After August, higher proportion of cases, $22.3 \%$ and $17.7 \%$ were occurred in July and September, respectively. Regarding the time of bite, more than half, $50.6 \%$ bites were reported at day time, from 5 $\mathrm{AM}$ to $7 \mathrm{PM}$. Most of the bites were reported/observed in the limb, $53.6 \%$ in lower limb and $43.4 \%$ in the upper limb. Very few bites were in the head, neck and trunk. Of the total, $49.1 \%$ participants reported that they were bitten by green snake and $30.9 \%$ could not mention the type of snake. There is a huge difference on species of the snakes so as the venom. Similar to our results, a study conducted in Pokhara shows majority of the victims were from Kaski district $65.34 \%$ and higher proportion of victims were aged between 10 - 59 years (86.81\%). And the maximum number of victims $49.45 \%$ belonged to farmers in occupation. Most of the snake bite cases were reported in the of month of May to October and the bite was mostly during day time $65.93 \%{ }^{6}$. The major signs we noted in this study are local swellings (57.7\%) and 144 (54.3\%) cases manifested hematological complication, which are managed by blood transfusions. To remove the venom is by transfusing a blood. PT/INR test is the reliable test to indicate the complication of venom and we found 123 (46.4\%) cases, PT/INR test did not clotted and blood transfusion was required.

\section{CONCLUSION}

Snake bite is still a major problem in developing countries like Nepal, causing significant morbidity and mortality. There is gross disparity in the management and outcomes of snake bite in different hospitals. Lack of transport facilities is common reason for causing delay in seeking treatment. Public health intervention should focus on improving victim's rapid transport mainly for people residing in far-off district to seek adequate treatment in a tertiary care hospital setting.

\section{Recommendation}

Further study is recommended in our part of the country to evaluate the protocol recommended by WHO for Southeast Asia region which considers the aggressive anti snake venom use within first few hours of innovation.

\section{REFERENCES}

1. Poudyal V, Paudal K, Rana N, Adhikari S. A hospital based study on snake bite poisoning in adults in the Western region of Nepal. Journal of Chitwan Medical College. 2016; 6(3): 33-38.

2. Kumar A, Dasgupta A, Biswas D, Sahoo S, Das S, Preeti $P$. Knowledge regarding snake bite in rural Bengal-Are they still lingering on myths and misconceptions. IAIM. 2015; 2(7): 36-41.

3. Pandey DP, Vohra R, Stalcup P, \& Shrestha BR. A season of snakebite envenomation: Presentation patterns, timing of care, anti-venom use, and case fatality rates from a hospital of South-central Nepal. Journal of Venom Research. 2016; 7: 1.

4. Hossain J, Biswas A, Rahman F, Mashreky SR, Dalal K, Rahman A. Snakebite Epidemiology in Bangladesh: A national community based health and injury survey. Health. 2016; 8: 479-486.

5. Nisar A, Rizvi F, Afzal M, Shafi MS. Presentation and complications of snakebite in a tertiary care hospital. J Coll Physicians Surg Pak. 2009; 19(5): 304-307.

6. Maskey A, Parajuli M, Kohli S, Baral S, Basnet S, Poudel N. Scenario of poisoning cases in adults admitted in Manipal Teaching Hospital, Pokhara, Nepal. Nepal Journal of Medical Sciences. 2012; 


\section{1(1): 23-26.}

7. Menon J, Joseph J, Jose M, Dhananjaya B, Oommen O. Clinical Profile and Laboratory Parameters in 1051 victims of snakebite from a single centre in Kerala, South India. J Assoc Physicians India. 2016; 63: 2229.

8. Ramakrishna C, Kanattu PS. A study of cardiac profile in patients with snake envenomation and its complications. International Journal of Clinical Medicine. 2017; 8(03): 167.

9. Biradar MV, Abhange R. A study of laboratory parameters prothrombin time and 20 minute WBCT in snake bite patients. International Medical Journal. October 10, 2015; 2: 697-701.

10. Kumar KP, Basheer M. Snake bite: Biochemical changes in blood after envenomation by viper and cobra. J Med Allied Sci. 2011; 1(1): 36-41.

11. Lakhotia M, Kothari D, Choudhary DR, Sharma S, Jain P. A case of saw scale viper snakebite presenting as pleuro-pericardial hemorrhage. J Indian Acad Clin Med. 2002; 3: 392-394.

12. Editorial. Snakebite - the neglected tropical disease. The Lancet. September 2015; 386. 